\title{
USO DA PROTEÍNA DERIVADA DA MATRIZ DO ESMALTE NO TRATAMENTO DE DEFEITOS ÓSSEOS PERIODONTAIS. UMA REVISÃO DA LITERATURA
}

\author{
USE OF ENAMEL MATRIX DERIVATIVE PROTEIN \\ IN THE TREATMENT OF PERIODONTAL SITES WITH \\ ANGULAR BONE DEFECTS. A REVIEW OF LITERATURE
}

\author{
RONALD SPEGEL ${ }^{1}$ \\ FÁBIO ANDRÉ DOS SANTOS² \\ GIBSON LUIZ PILATTI
}

1 Especialista em Periodontia pela EAP-ABO Ponta Grossa - PR

2 Professor do Departamento de Odontologia UEPG e do Curso de Especialização em Periodontia da EAP-ABO/Ponta Grossa - PR

\begin{abstract}
RESUMO
Nas últimas duas décadas, um grande enfoque têm sido dado às terapias regenerativas para a resolução de defeitos ósseos periodontais. Uma nova forma de material para ser usado nesse intuito são as proteínas derivadas da matriz do esmalte (MDE). O constituinte dominante da matriz do esmalte, amelogenina, exerce sua função durante a formação radicular induzindo a formação das estruturas de suporte do dente. Esta afirmação tem sido suportada por estudos histológicos, incluindo defeitos periodontais em humanos, em que, o seu produto comercial (Emdogain ${ }^{\circledR}$ ) foi utilizado. Estudos clínicos têm mostrado que o uso da MDE durante a cirurgia periodontal leva a um significante ganho de inserção, redução na profundidade de PUBLICATIO UEPG - Biological and Health Sciences, 8 (1): 7-21, 2002.
\end{abstract}


sondagem e ganho de osso alveolar, quando comparada com a terapia periodontal convencional, porém não mostrando significativamente melhores resultados em relação a outras terapias regenerativas.

Palavras-chave: tratamento periodontal; regeneração periodontal; proteínas da matriz do esmalte

\section{Introdução}

O objetivo da terapia periodontal tem sido dirigido ultimamente, não apenas ao diagnóstico e controle da doença, mas também para a regeneração do aparato de inserção (osso alveolar, cemento, ligamento periodontal) perdido. Para alcançar esse objetivo diferentes materiais de enxerto têm sido usados (BOWEN et al., 1989; MELLONIG, 1999; PAGE, 1993; PONTORIERO et al., 1999; RASPERINI et al., 1999; SILVESTRI et al., 2000; WILSON, 1999).

No mercado são lançados freqüentemente novos produtos que prometem restabelecer os tecidos periodontais de suporte. Um destes produtos é o Emdogain ${ }^{\circledR}$, uma proteína derivada da matriz orgânica do esmalte. Este material é composto principalmente por amelogenina, extraída de germes dentais de suínos durante o processo de odontogênese. A amelogenina tem importante papel coadjuvante no desenvolvimento do cemento acelular, ligamento periodontal e osso alveolar(BROOKS, 1995; HAMMARSTRÖM, 1997; HAMMARSTRÖM et al.,1997; HIROOKA, 1998; SCULEAN et al., 1999). Têm sido demonstrado que este tipo de material melhora in vitro a proliferação e síntese proteica das células do ligamento periodontal (GESTRELIUS et al.,1997; GESTRELIUS et al., 1997; HOANG et al., 2000; LYNCH et al., 1991; SLAVKIN, 1976).

Esses precursores da formação do esmalte permaneceram essencialmente imutáveis durante a evolução das espécies, portanto, existe uma grande semelhança entre as proteínas de esmalte humano e a dos suínos. Avaliação histológica e estudos clínicos em humanos têm demonstrado a sua segurança e eficácia (HAMMARSTRÖM, 1997; HAMMARSTRÖM et al., 1997; HEIJL et al., 1997).

Este trabalho tem o propósito de fazer uma revisão bibliográfica dos

PUBLICATIO UEPG - Ciências Biológicas e da Saúde, 8 (1): 7-21, 2002. 
estudos realizados com as proteínas derivadas da matriz do esmalte, procurando discutir sobre a sua real capacidade em regenerar os tecidos periodontais perdidos pela doença.

\section{Revisão da literatura}

Com o objetivo de facilitar a leitura e entendimento dos estudos com o Emdogain ${ }^{\circledR}$, dividimos a revisão dos trabalhos em: estudos in vitro, histológicos e clínicos.

\section{1. Estudos in vitro}

Brooks et al. (1995) realizaram um trabalho envolvendo biologia molecular e verificaram que existem diversas proteínas presentes na matriz do esmalte, sendo a amelogenina a mais encontrada, representando cerca de $90 \%$ da matriz do esmalte.

Com o objetivo de verificar a influência da matriz derivada de esmalte (MDE) sobre as células do ligamento periodontal de pré-molares humanos, Gestrelius et al., (1997) realizaram um estudo no qual, demonstraram que a MDE aumenta a proliferação de células do ligamento periodontal, mas não de células epiteliais. Observaram também que MDE aumenta a produção de proteínas pelas células do ligamento periodontal e promove a formação de nódulos minerais por estas.

Em 1998, Petinaki et al. fizeram um estudo para avaliar a influência do Emdogain ${ }^{\circledR}$, sobre o sistema imunológico. Para tanto, foram colocados linfócitos de dez doadores saudáveis em um meio de cultura, juntamente com diferentes concentrações de Emdogain ${ }^{\circledR}$. A partir disso foi determinada a proliferação celular, presença de antígenos e a produção de citocinas e imunoglobulinas. Como resultado, observou-se um pequeno aumento na proliferação de linfócitos em contato com o Emdogain ${ }^{\circledR}$, sem afetar outras populações celulares.

Analisando o efeito da matriz derivada do esmalte sobre a proliferação de células do epitélio oral, Kawasa et al. (2000) mostraram que a prote- 
10

ína promovia uma redução na migração das mesmas.

Hoang et al. (2000) estudaram crescimento de células do ligamento periodontal humano (LP) e de osteosarcoma (MG-63), comparando o efeito da matriz derivada do esmalte (MDE) com o fator de crescimento derivado de plaquetas (PDGF) e o fator de crescimento semelhante à insulina (IGF). Concluíram que a aplicação da proteína derivada da matriz esmalte pode favorecer a regeneração periodontal, especificamente modificando a migração e proliferação de células do ligamento periodontal.

\section{2. Estudos histológicos}

Em 1997, Hammarström realizou um estudo para verificar a presença e a distribuição da amelogenina na região apical de pré-molares humanos. Utilizou 5 dentes, extraídos por razões ortodônticas que possuíam os ápices abertos e cerca de $1 / 2 \mathrm{ou}^{2} /{ }_{3}$ das raízes formadas. Os resultados mostraram que a amelogenina ocorria no ápice do dentes em formação. Constatou também que um tecido não celularizado, semelhante ao cemento, formou-se na superfície da matriz do esmalte quando a mesma foi exposta a células mesenquimais do folículo dental. $\mathrm{O}$ autor chegou à conclusão de que a proteína derivada da matriz do esmalte (MDE) pode ser utilizada para a regeneração do cemento acelular de fibras extrínsicas.

Para avaliar o efeito da aplicação da proteína derivada de esmalte (MDE) utilizando diferentes veículos (propilenoglicol, hidroxietilcelulose e dextrana), Hammarström et al. (1997) criaram cirurgicamente defeitos ósseos na face vestibular de pré-molares (deiscência) de macacos. A MDE foi aplicada na superfície radicular exposta, utilizando diferentes veículos. Após 8 semanas os animais foram sacrificados e os dentes removidos para análise histológica. Os resultados mostraram formação cementária variando de 60 a $80 \%$, sendo a combinação da amelogenina com proprileno glicol a mais eficiente.

Heijl (1997) avaliou os aspectos histológicos e a efetividade da MDE no tratamento de um defeito periodontal em forma de deiscência no dente 31 de um paciente com 45 anos de idade. Após 4 meses o dente foi removido em bloco para análise histológica. Os resultados obtidos caracterizavam-se por uma cicatrização periodontal em que se observou a formação de

PUBLICATIO UEPG - Ciências Biológicas e da Saúde, 8 (1): 7-21, 2002. 
cemento acelular de fibras extrínsecas fortemente aderido à dentina com fibras conjuntivas inseridas perpendicularmente à superfície radicular. Observou-se ainda a presença de osso alveolar com fibras inseridas e em continuidade com o ligamento periodontal pré-existente.

Em 1998, Araújo e Lindhe avaliaram clínica e histologicamente a utilização do Emdogain ${ }^{\circledR}$ em defeitos de furca classe 3 criados e cronificados por 2 meses em pré-molares de cães. Os resultados mostraram que a quantidade de cemento e osso formados foram similares nos grupos teste (raspagem+membrana+MDE) e controle (raspagem+membrana). No entanto, no lado teste, houve a formação de cemento acelular na porção apical do defeito, diferente do cemento da porção coronária (cemento celular). No lado controle houve a formação de cemento celular em toda a extensão. Os autores chegaram à conclusão de que a MDE pode induzir a formação de cemento acelular.

Com o objetivo de avaliar o uso da regeneração tecidual guiada (RTG) em associação com a MDE, Sculean et al. (1999) trataram 14 pacientes com defeitos periodontais angulares contra-laterais. Um grupo de defeitos recebeu durante o tratamento cirúrgico a aplicação do Emdogain ${ }^{\circledR}$ e o outro grupo recebeu uma membrana reabsorvível (RTG) mais a aplicação do Emdogain ${ }^{\circledR}$. Os resultados clínicos após 6 meses revelaram que no grupo MDE a profundidade de sondagem (PS) reduziu para 5,6 $\pm 1,3 \mathrm{~mm}$ e o nível de inserção clínica (NIC) para 9,1 $\mathrm{mm} \pm 1,5 \mathrm{~mm}$. No grupo RTG a PS foi de $5,6 \pm 1,3 \mathrm{~mm}$ e o NIC de 10,1 $\pm 1,5 \mathrm{~mm}$. Os autores concluíram que ambos os tratamentos favoreceram a obtenção de nova inserção clínica.

Boyan et al. (2000) realizaram um estudo em ratos, sobre a neoformação óssea induzida pelo enxerto de osso desmineralizado humano (DFDBA), juntamente com a matriz derivada de esmalte (MDE), implantadas no tecido muscular. Os resultados mostraram que a MDE não demonstrou capacidade osteindutora, apenas osteocondutora.

Rocha (2000) realizou um trabalho em cães para avaliar a formação de novo cemento e a regeneração periodontal em defeitos de furca grau três em cães utilizando o Emdogain ${ }^{\circledR}$. Foram utilizados $3^{\circ}$ pré-molares inferiores, sendo os defeitos criados e cronificados por 4 semanas. Um lado recebeu cirurgia periodontal para raspagem (controle) e o outro (teste) os mesmos procedimentos associados com a aplicação do Emdogain ${ }^{\circledR}$. O período de avaliação foi de 150 dias. O estudo concluiu que não houve diferença estatisticamente significante quando se utilizou ou não a MDE para as variáveis: formação cementária, migração epitelial, tecido conjuntivo e área de PUBLICATIO UEPG - Biological and Health Sciences, 8 (1): 7-21, 2002. 
12

osso neoformado. Além disso, não houve completa regeneração da lesão de furca em nenhuma das modalidades de tratamento.

\section{3. Estudos clínicos}

Procurando avaliar a segurança clínica do Emdogain ${ }^{\circledR}$ no tratamento de defeitos periodontais, Zetterström et al. (1997) realizaram um estudo clínico com 107 pacientes tratados com MDE juntamente com retalho de Widman modificado (RWM), e compararam a um grupo controle, tratado somente com RWM. Os resultados clínicos e radiográficos após 3 anos de acompanhamento, mostraram um maior preenchimento ósseo no grupo teste em relação ao controle.

Heijl et al. (1997) realizaram um estudo em humanos utilizando o Emdogain ${ }^{\circledR}$ juntamente com o retalho de Widman modificado (teste), tendo como controle o mesmo procedimento cirúrgico associado com gel pacebo (propilenoglicol). O estudo envolveu 33 pacientes com 35 pares de defeitos ósseos de uma ou duas paredes com profundidade a sondagem maior ou igual a $6 \mathrm{~mm}$. Foram avaliados o ganho de inserção clínica e radiográfica após 8, 16 e 36 meses. Após 8 meses os resultados mostraram no lado teste um ganho de inserção clínica de 2,1 mm e no lado controle de 1,5 mm. Com 16 meses o ganho foi de 2,3 mm (lado teste) e 1,7 mm (lado controle); e ao 36 meses foi de 2,2 mm (teste) e 1,7 (controle), com diferenças estatisticamente significantes entre os grupos a cada período. O ganho radiográfico no lado teste foi de $2,6 \mathrm{~mm}$ correspondendo a $66 \%$ de preenchimento do defeito.

Sculean et al. (1999) fizeram uma pesquisa em que trataram 32 defeitos ósseos de duas e três paredes com profundidade de sondagem mínima de $6 \mathrm{~mm}$ em 28 pacientes utilizando Emdogain ${ }^{\circledR}$. Os resultados após 8 meses mostraram uma redução de $4,4 \mathrm{~mm}$ para a profundidade de sondagem, um ganho de 3,0mm de inserção clínica e um aumento de 1,5mm na recessão gengival.

Mellonig (1999) descreveu dois casos clínicos em que o Emdogain ${ }^{\circledR}$ foi utilizado no tratamento de defeitos ósseos periodontais. O primeiro caso, apresentava um defeito horizontal em um pré-molar superior, com perda de inserção clínica de $8 \mathrm{~mm}$. Após seis meses do tratamento, não havia sangramento e constatou-se um ganho de inserção clínica de $4 \mathrm{~mm}$. O sePUBLICATIO UEPG - Ciências Biológicas e da Saúde, 8 (1): 7-21, 2002. 
gundo, tinha (canino inferior) uma profundidade a sondagem de $8 \mathrm{~mm}$ e perda de inserção clínica de $9 \mathrm{~mm}$. Após seis meses da cirurgia, a profundidade a sondagem era de $3 \mathrm{~mm}$ e houve um ganho de inserção clínica de $4 \mathrm{~mm}$. Este dente, previamente programado para exodontia por razões protéticas, foi removido em bloco e avaliado histologicamente, onde se observou a formação de novo osso, cemento e ligamento periodontal coronariamente à base do defeito. Acima do cemento pré-existente, depositou-se uma fina camada de cemento acelular, estando as fibras do ligamento periodontal paralelamente dispostas à superfície da raiz.

Heden et al., (1999) realizaram um estudo em que aplicaram o Emdogain ${ }^{\circledR}$ no tratamento de defeitos ósseos. Foram tratados 108 pacientes (145 defeitos), sendo analisadas a redução da profundidade a sondagem e ganho de inserção. Os resultados demonstraram um ganho de inserção clínica de 4,6mm em média e uma redução de profundidade a sondagem de 5,2mm. Em $87 \%$ de todos os sítios tratados houve um ganho de inserção maior que $2 \mathrm{~mm}$, havendo na análise radiográfica um preenchimento médio de $69 \%$. Em $43 \%$ dos defeitos o preenchimento ósseo foi maior ou igual a $80 \%$.

Em 1999, Pontoriero et al. conduziram um estudo clínico para analisar o uso de membranas juntamente com a MDE. Foram avaliados 40 pacientes que possuíam perda de inserção periodontal e presença de dois defeitos ósseos contra laterais. Os pacientes foram divididos em quatro grupos com 10 pacientes, sendo que, três grupos receberam tratamento com membranas (Guidor ${ }^{\circledR}$, Resolut ${ }^{\circledR}$ e e-PTFE) e um grupo foi tratado com Emdogain ${ }^{\circledR}$. Os defeitos controles foram tratados com cirurgia periodontal, sem a colocação de membrana e com a aplicação de um gel placebo (propilenoglicol). Os resultados demonstraram que, após doze meses, ocorreu uma redução na profundidade de sondagem e na perda de inserção clínica nos grupos tratados com regeneração tecidual guiada e com Emdogain ${ }^{\circledR}$, mostrando-se superiores em relação ao controle.

Heden (2000) pesquisou o uso do Emdogain ${ }^{\circledR}$ em 72 defeitos ósseos de 61 pacientes. Os parâmetros avaliados foram a profundidade de sondagem, nível de inserção e ganho ósseo pela análise radiográfica. Após doze meses, a redução média na profundidade de sondagem foi de $4,7 \mathrm{~mm}$ e a média de ganho de inserção foi de 4,2mm. Radiograficamente houve um preenchimento ósseo médio de $70 \%$.

Rasperini et al. (2000) avaliaram clínica e histologicamente, os resultados obtidos com o tratamento de uma recessão gengival em um canino PUBLICATIO UEPG - Biological and Health Sciences, 8 (1): 7-21, 2002. 
14

inferior com enxerto de tecido conjuntivo subepitelial, juntamente com a aplicação da proteína derivada da matriz do esmalte (Emdogain $\left.{ }^{\circledR}\right)$. A recessão gengival era de $6 \mathrm{~mm}$ com $1 \mathrm{~mm}$ de profundidade a sondagem e ausência de mucosa queratinizada. Após 6 meses o dente foi extraído em bloco para análise histológica, na qual foi demonstrado um ganho de inserção de $2 \mathrm{~mm}$ e um aumento de $3 \mathrm{~mm}$ na largura da mucosa queratinizada. $\mathrm{O}$ estudo histológico evidenciou a migração do epitélio juncional de 1,2 mm em sentido apical, constatou-se também a formação de novo cemento e uma fina camada de novo osso com ligamento periodontal inserido.

Uma avaliação da eficácia do uso da MDE isoladamente ou em associação ao enxerto ósseo bovino foi feita por Lekovic et al. (2000) para o tratamento de defeitos ósseos periodontais. Foram selecionados 21 pares de defeitos com 2 ou 3 paredes em 21 pacientes. A reentrada cirúrgica foi feita seis meses após, constatando-se uma redução significativa na profundidade de sondagem no grupo que associou os dois tipos de materiais (3,43 $\pm 1,32 \mathrm{~mm}$ nos sítios vestibulares e 3,36 $\pm 1,35 \mathrm{~mm}$ nos sítios linguais), quando comparados com o grupo do Emdogain ${ }^{\circledR}(1,91 \pm 1,42 \mathrm{~mm}$ nos sítios vestibulares e 1,85 \pm 1,38mm nos sítios linguais). Em relação ao ganho de inserção, o grupo Emdogain $®+$ osso bovino também apresentou um desempenho superior (3,13 $\pm 1,41 \mathrm{~mm}$ nos sítios vestibulares e 3,11 $\pm 1,39 \mathrm{~mm}$ nos linguais) ao do grupo que utilizou Emdogain ${ }^{\circledR}$ isoladamente $(1,72 \pm 1,33 \mathrm{~mm}$ nos sítios vestibulares e 1,75 $\pm 1,37 \mathrm{~mm}$ nos sítios linguais).

Silvestri et al. (2000) compararam os resultados obtidos com o tratamento de defeitos ósseos empregando MDE, regeneração tecidual guiada (RTG) com membrana reabsorvível e retalho de Widman modificado (RWM). Para isto foram selecionados 30 pacientes que apresentavam defeitos ósseos com profundidade maior ou igual a $4 \mathrm{~mm}$. Os pacientes foram divididos em 3 grupos $(\mathrm{n}=10)$, sendo tratados com os diferentes métodos testados. Os resultados não demonstraram diferenças estatisticamente significantes entre os grupos tratados com MDE quanto com a RTG, os quais mostraram-se superiores ao grupo tratado com RWM.

\section{Discussão}

Até a década de 40, as modalidades de tratamento periodontal existentes consistiam basicamente na raspagem das raízes dentais e muitas vezes na extração dos dentes afetados pela doença. Aos poucos, as cirurgias ressectivas foram sendo utilizadas juntamente com a raspagem radicular PUBLICATIO UEPG - Ciências Biológicas e da Saúde, 8 (1): 7-21, 2002. 
para devolver uma anatomia periodontal condizente com saúde, ou seja, que o paciente pudesse higienizar adequadamente os locais tratados. A partir da década de 80 , os pesquisadores começaram a perceber que o maior determinante no sucesso do tratamento periodontal era o controle da microbiota sub e supragengival, através da raspagem e alisamento radicular, tornando a terapia periodontal não cirúrgica como parte indispensável do tratamento (HIROOKA, 1998; PAGE, 1993; WILSON, 1999).

Atualmente, além do controle da inflamação periodontal, busca-se também modalidades cirúrgicas que possam regenerar o aparato de inserção perdido. Dentre as modalidades de tratamento regenerativo, destaca-se o uso de biomateriais para serem implantados em defeitos periodontais. Ultimamente, com o desenvolvimento da engenharia genética, fatores de crescimento como PDGF (fator de crescimento derivado de plaquetas) e IGF (fator de crescimento semelhante à insulina) também vêm sendo investigados dentro das terapias regenerativas (BROOKS et al., 1995; KAWASE et al., 2000; LYNCH et al., 1991; SLAVKIN, 1976)

Com o objetivo de restituir o periodonto perdido pela doença, promover a regeneração periodontal, desenvolveu-se a técnica de regeneração tecidual guiada, a qual teria por objetivo prevenir a migração dos tecidos epitelial e conjuntivo gengival ao longo da superfície radicular durante o reparo. Ao mesmo tempo, a membrana utilizada permitiria uma estabilidade do coágulo, favorecendo a proliferação de células remanescentes do ligamento periodontal, tornando possível a formação de novo cemento, ligamento periodontal e osso alveolar. No entanto, sua previsibilidade ainda é questionada (ARAÚJO et al., 1998; HAMMARSTRÖM et al., 1997; HEIJL, 1997; HIROOKA, 1998; SILVESTRI et al., 2000; SLAVKIN, 1976).

Recentemente, pesquisas têm enfocado a utilização de uma proteína derivada da matriz do esmalte obtidas de dente em desenvolvimento de suínos (HAMMARSTRÖM, 1997; HAMMARSTRÖM et al., 1997; HEIJL et al., 1997; ZETTESTRÖM et al., 1997). Essa proteína conhecida como amelogenina, constitui cerca de $90 \%$ da matriz do esmalte dental. A partir da mesma, foi produzida uma derivação estável, a qual foi liofilizada com o objetivo de proporcionar a sua utilização clínica, apresentando o nome comercial de Emdogain ${ }^{\circledR}$. Segundo seu fabricante, esse material é capaz de regenerar o cemento em dentes afetados pela doença periodontal.

Segundo Slavkin (1976), um dos principais tecidos envolvidos na regeneração periodontal é o cemento. A deposição do cemento é dependente da degeneração da bainha epitelial de Hertwig. Os cementoblastos deriPUBLICATIO UEPG - Biological and Health Sciences, 8 (1): 7-21, 2002. 
vados das células mesenquimais depositam cemento sobre a superfície dentinária mineralizada da raiz em formação. Fibras do ligamento periodontal migram depois sobre esta superfície e são incorporadas ao cemento (fibras de Sharpey), através da deposição da matriz ao redor destas fibras.

Em 1997, Gestrelius et al. realizaram um estudo in vitro para demonstrar as propriedades do Emdogain ${ }^{\circledR}$ e constataram que ele se agregava e tornava-se praticamente insolúvel em $\mathrm{pH}$ fisiológico e temperatura corporal, bem como a adsorção dessa proteína pela hidroxiapatita, colágeno e superfície radicular. Mostraram que o propilenoglicol foi um bom veículo quando comparado com hidroxietilcelulose e dextrana. Em outro estudo, Gestrelius et al. (1997) demonstraram que a proteína derivada da matriz do esmalte aumentou a proliferação das células do ligamento periodontal, mas não das células epiteliais. Esses resultados são compatíveis com aqueles obtidos por Hoang (2000) e por Kawase et al. (2000).

Em um outro estudo in vitro, Petinaki et al. (1998) determinaram que o uso do Emdogain ${ }^{\circledR}$ provocou a apenas discreta alteração na produção de linfócitos e outras frações celulares. O biomaterial também favoreceu a proliferação de células do ligamento periodontal humano em meios de cultura. Estes resultados foram confirmados por Hoang et al. (2000). Já Boyan et al. (2000) não considerou o Emdogain ${ }^{\circledR}$ um material osteoindutivo, e sim osteocondutor, pois não teve a capacidade de promover a formação óssea quando implantado em músculo de ratos.

Em relação aos estudos histológicos, a sua avaliação torna-se difícil, devido ao escasso número de trabalhos na literatura e por existirem diferenças de metodologia nos trabalhos(ARAÚJO et al., 1998; HAMMARSTRÖM et al., 1997; MELLONIG, 1999; RASPERINI et al., 2000). Os resultados obtidos por meio de análise histométrica demonstraram uma variação muito grande para todas as variáveis avaliadas. Isso pode ser devido à variação genética, bioquímica ou imunológica dos animais utilizados (ROCHA, 2000).

Gestrelius et al. (1997) constataram que o Emdogain ${ }^{\circledR}$, quando aplicado em dentes em que tiveram parte do cemento removido, induziu uma maior proliferação de fibroblastos sobre a superfície radicular. Além disso, o propilenoglicol foi o melhor veículo para aplicação da proteína derivada de esmalte (Emdogain $\left.{ }^{\circledR}\right)$, em concordância com o estudo de Hammarström et al. (1997).

Foi possível demonstrar a formação de um tecido não celularizado PUBLICATIO UEPG - Ciências Biológicas e da Saúde, 8 (1): 7-21, 2002. 
semelhante ao cemento sobre a superfície radicular quando se aplicou o Emdogain ${ }^{\circledR}$ sobre as células do folículo dental de dentes humanos e de macacos (HAMMARSTRÖM, 1997). Esse mesmo autor, também em 1997, demonstrou regeneração periodontal com formação cementária, variando de 60 a 80\% do defeito original, quando da aplicação de Emdogain ${ }^{\circledR}$ em deiscências periodontais criadas cirurgicamente em macacos.

Realizando um estudo em cães, Rocha (2000) avaliou o Emdogain ${ }^{\circledR}$ em defeitos de furca grau dois, não observando diferenças significativas entre os grupos tratados com Emdogain ${ }^{\circledR}$ e o controle. Estes resultados foram diferentes dos encontrados por Hammarström (1997), Hammarström et al. (1997) e Heijl (1997), que observaram a formação de cemento acelular com fibras extrínsecas, osso alveolar e fibras do ligamento periodontal inseridas com o uso do Emdogain ${ }^{\circledR}$.

Estudos de Sculean et al. (1999) observaram resultados semelhantes quanto ao ganho de inserção clínica quando se comparou a regeneração tecidual guiada e o Emdogain ${ }^{\circledR}$ no tratamento de defeitos intra-ósseos. Resultados também confirmados por Pontoriero et al. (1999), que comparando a utilização do Emdogain ${ }^{\circledR}$ com membranas (regeneração tecidual guiada - RTG) no tratamento de defeitos ósseos, não observaram benefícios clínicos adicionais em relação ao uso isolado do Emdogain ${ }^{\circledR}$. Silvestri et al. (2000) encontraram resultados superiores utilizando o Emdogain ${ }^{\circledR}$ associado à RTG em relação ao retalho de Widman modificado. Os mesmos resultados forma observados no estudo de Zetteström et al. (1997).

A associação do Emdogain $₫$ com outros biomateiais, como por exemplo o osso bovino desmineralizado, poderia prolongar o tempo de permanência da proteína no defeito ósseo, segundo Lekovic et al., (2000), aumentando assim sua eficácia.

O uso clínico da matriz derivada do esmalte (Emdogain $\left.{ }^{\circledR}\right)$ caracteriza-se pela facilidade de aplicação, assim como o menor risco de complicações pós-operatórias, como ocorre com a regeneração tecidual guiada, como a possibilidade de exposição da membrana, infecção do sítio tratado, com a conseqüente diminuição do tecido neoformado. Apesar de todas estas vantagens, o custo do material no mercado nacional ainda é muito alto. Além disso, estudos clínicos e histológicos adicionais são necessários para determinar os reais benefícios clínicos que a matriz derivada do esmalte pode proporcionar na constante busca pela regeneração periodontal. 


\title{
4. Conclusão
}

A partir dos estudos revisados podemos concluir que:

1- Novos biomateriais estão sendo desenvolvidos para tentar se obter a regeneração das estruturas periodontais perdidas pela doença, porém os resultados ainda são controversos.

2- A utilização da matriz derivada do esmalte (Emdogain $\left.{ }^{\circledR}\right)$, embora tenha mostrado bons resultados na regeneração do cemento em pesquisas histológicas com animais, nos estudos clínicos as diferenças não foram significativas quando da comparação com outras técnicas regenerativas.

3- Estudos adicionais são necessários para confirmar sua real contribuição para as terapias regenerativas.

Recebido para publicação em 27/03/2001.

Aceito para publicação em 15/02/2002.

\begin{abstract}
In the last two decades, a great emphasis has been given for the regenerative therapies to treat periodontal bone defects. In this field, a relatively new biological approach is the use of enamel matrix derivative proteins (EMD) during periodontal surgery. The dominant constituent of the enamel matrix, amelogenin, is expressed during natural root formation and induces the development of the tooth supporting structures. This has been supported by histological examination including human natural periodontal defects treated with surgery and EMD application. Clinical studies showed that EMD application during periodontal surgery lead to a significant probing attachment gain, probing pocket depth reduction and alveolar bone gain. Compared to other regenerative therapies using barrier membranes in angular intrabony defects, EMD demonstrated similar probing depth reduction and probing attachment level gain, showing a better improvement when compared to the open flap debridment alone.
\end{abstract}

Key words: periodontal treatment; periodontal regeneration; enamel matrix derivative proteins

Endereço para contato: fasantos@interponta.com.br 


\section{REFERÊNCIAS}

1 ARAÚJO, M. G.; LINDHE, J. GTR treatment of degree III furcation defects following application of enamel matrix proteins. An experimental study in dogs. $\mathbf{J}$ Clin Periodontol, v. 25, n. 6, p. 524-530, 1998.

2 BOWEN, J.A. et al. Comparison of decalcified freeze-dried bone allograft and porous particulate hydroxyapatite in human periodontal osseous defects. $\mathbf{J}$ Periodontol, v. 60, n. 12, p. 647-654, 1989.

3 BOYAN, B.D. et al. Porcine fetal enamel matrix derivative enhances bone formation induced by demineralized freeze dried bone allograft in vivo. J Periodontol, v. 71, n. 8, p. 1278-1286, 2000.

4 BROOKS, S.J. et al. Biochemistry and molecular biology of amelogenin proteins of developing dental enamel. Arch Oral Biol, v. 40, n. 1, p. 1-14, 1995.

5 GESTRELIUS, S. et al. Formulation of enamel matrix derivative for surface coating. Kinetics and cell colonization. J Clin Periodontol, v. 24, n. 9, p. 678-684, 1997.

6 GESTRELIUS, S. et al. In vitro studies on periodontal ligament cells and enamel matrix derivative. J Clin Periodontol, v. 24, n. 9, p. 685-692, 1997.

7 HAMMARSTRÖM, L. Enamel matrix ,cementum development and regeneration. J Clin Periodontol, v. 24, n. 9, p. 658-668, 1997.

8 HAMMARSTRÖM, L.; HEIJL, L.; GESTRELIUS, S. Periodontal regeneration in a bucal dehiscence model in monkeys after application of enamel matrix proteins. J Clin Periodontol, v. 24, n. 9, p. 669-677, 1997.

9 HEDEN, G. A case report study of 72 consecutive Emdogain-treated intrabony periodontal defects: clinical and radiographic findings after 1 year. Int J Periodontics Restorative Dent, v. 20, n. 2, p. 127-139, 2000.

10 HEDEN, G.; WENNSTRÖM, J.; LINDHE, J. Periodontal tissue alterations following Emdogain treatment of periodontal sites with angular bone defects. A series of case reports. J Clin Periodontol, v. 26, n. 12, p. 855-60, 1999.

11 HEIJL, L. Periodontal regeneration with enamel matrix derivative in one human experimental defect. A case report. J Clin Periodontol, v. 24, n. 9, p. 693-696, 1997.

12 HEIJL, L. et al. Enamel matrix derivative (Emdogain) in the treatment of intrabony periodontal defects. J Clin Periodontol, v. 24, n. 9, p. 705-714, 1997. 
13 HIROOKA, H. The biologic concept for the use of enamel matrix protein: true periodontal regeneration. Quintessence Int, v. 29, n. 10, p. 621-630, 1998.

14 HOANG, A,M.; OATES, T.W.; COCHRAN, D.L. In vitro wound healing responses to enamel matrix derivative. J Periodontol, v. 71, n. 8, p.1270-1277, 2000.

15 KAWASE, T. et al. Cytostatic action of enamel matrix derivative (Emdogain) on human oral squamous cell carcinoma-derived SCC25 epithelial cells. J Periodontal Res, v. 35, n. 5, p. 291-300, 2000.

16 LEKOVIC, V. et al. A comparison between enamel matrix proteins used alone or in combination with bovine porous bone mineral in the treatment of intrabony periodontal defects in humans. J Periodontol, v. 71, n. 7, p. 1110-11160, 2000.

17 LYNCH, S.E. et al. The effects of short-term application of a combination of platelet-derived and insulin-like growth factors on periodontal wound healing. $\mathbf{J}$ Periodontol, v. 62, n. 7, p. 458-467, 1991.

18 MELLONIG, J.T. Enamel matrix derivative for periodontal reconstructive surgery: technique and clinical and histologic case report. Int $\mathbf{J}$ Periodontics Restorative Dent, v. 19, n. 1, p. 8-19, 1999.

19 PAGE, R. C. Periodontal therapy: prospects for the future. J Periodontol, v. 64, n. 8(suppl.), p. 744-753, 1993.

20 PETINAKI, E.; NIKOLOPOULOS, S.; CASTANAS, E. Low stimulation of peripheral lymphocytes, following in vitro application of Emdogain. J Clin Periodontol, v. 25, n. 9, p. 715-720, 1998.

21 PONTORIERO, R.; WENNSTRÖM, J.; LINDHE, J. The use of barrier membranes and enamel matrix proteins in the treatment of angular bone defects. A prospective controlled clinical study. J Clin Periodontol, v. 26, n. 12, p. 833-840, 1999.

22 RASPERINI, G.; RICCI, G.; SILVESTRI, M. Surgical technique for treatment of intrabony defects with enamel matrix derivative (Emdogain): 3 cases reports. Int J Periodontics. Restorative. Dent, v. 19, n. 6, p. 578-587, 1999.

23 RASPERINI, G. et al. Clinical and histologic evaluation of human gingival recession treated with a subepithelial connective tissue graft and enamel matrix derivative (Emdogain): a case report. Int J Periodontics. Restorative Dent, v. 20, n. 3, 269-275, 2000.

24 ROCHA, E.F. O uso da proteína da matriz do esmalte no tratamento de lesões de furca grau dois. Estudo histométrico em cães. Araraquara, 2000. 103 
p. Dissertação (Mestrado em Odontologia - Periodontia). Faculdade de Odontologia de Araraquara, Universidade Estadual “Júlio de Mesquita Filho”.

25 SCULEAN, A. et al. Comparison of enamel matrix proteins and bioabsorbable membranes in the treatment of intrabony periodontal defects. A split-mouth study. J Periodontol, v. 70, n.3, p. 255-262, 1999.

26 SCULEAN, A. et al. Healing of human intrabony defects following treatment with enamel matrix proteins or guided tissue regeneration. J Periodontal Res, v. 34, n. 6, p. 310-322, 1999.

27 SILVESTRI, M. et al. Comparison of treatments of intrabony defects with enamel matrix derivative, guided tissue regeneration with nonresorbable membrane and Widman modified flap. A pilot study. J Clin Periodontol, v. 27, n. 8, p. 603-610, 2000.

28 SLAVKIN, H. C. Towards a cellular and molecular understanding of periodontics. Cementogenesis revisited. J. Periodontol, v. 47, n. 5, p. 249-255, 1976.

29 WILSON, T. G. Periodontal Regeneration Enhanced. Clinical applications of Enamel Matrix Proteins. Illinois: Quintessence Books, 1999, 73 p.

30 ZETTESTRÖM, O. et al. Clinical safety of enamel matrix derivative (Emdogain) in the treatment of periodontal defects. J Clin Periodontol, v. 24, n. 2, p. 697-704, 1997. 